\title{
On the origin of the selectivity of plasmidic H-NS towards horizontally acquired DNA. Linking H-NS oligomerization and cooperative DNA binding
}

Carlos Fernández-de-Alba ${ }^{1,2}$, Nicholas S. Berrow ${ }^{2}$, Raquel Garcia-Castellanos ${ }^{2}$, Jesús García $^{2 *}$, and Miquel Pons ${ }^{1,2 *}$

\author{
${ }^{1}$ Departament de Química Orgànica. Universitat de Barcelona. Martí i Franquès, 1-11 \\ 08028-Barcelona \\ ${ }^{2}$ Institute for Research in Biomedicine (IRB Barcelona). Baldiri Reixac, 10-12 08028- \\ Barcelona. Spain \\ *to whom correspondence should be addressed: mpons@ub.edu; \\ jesus.garcia@irbbarcelona.org
}

\begin{abstract}
The nucleoid-associated protein H-NS is a global modulator of the expression of genes associated with adaptation to environmental changes. A variant of H-NS expressed in the R27 plasmid was previously shown to selectively modulate the expression of horizontally acquired genes, with minimal effects on core genes that are repressed by the chromosomal form of H-NS. Both H-NS proteins are formed by an oligomerization domain and a DNA-binding domain, which are connected by a linker that is highly flexible in the absence of DNA.

We studied DNA binding by means of oligomer-forming chimeric proteins in which domains of the chromosomal and plasmidic variants are exchanged, as well as in monomeric truncated forms containing the DNA-binding domain and variable portions of the linker. Point mutations in the linker were also examined in full-length and truncated H-NS constructs. These experiments show that the linker region contributes to DNA binding affinity and that it is a main component of the distinct DNA binding properties of chromosomal and plasmidic H-NS.

We propose that interactions between the linker and DNA limit the flexibility of the connection between H-NS oligomerization and DNA binding and provide an allosteric
\end{abstract}


indirect readout mechanism to detect long-range distortions of DNA, thus enabling discrimination between core and horizontally acquired DNA.

Keywords: Allosteric interactions, Indirect DNA readout, Xenogeneic DNA, NMR, EMSA

Abbreviations used: DBD, DNA-binding domain; EMSA, Electrophoretic Mobility Shift Assay; HSQC, heteronuclear single-quantum correlation; Ni-NTA, $\mathrm{Ni}^{2+}$ nitrilotriacetate; NMR, Nuclear Magnetic Resonance.

\section{Introduction}

Genetic diversity originating from horizontal gene transfer (HGT) is a major contributor to evolution and responsible for the capacity of bacteria to colonize new environments, including human hosts. The acquired genes are retained when they confer an adaptive advantage in a certain niche; however, gene acquisition may bring about a fitness cost. ${ }^{1,2}$ Understanding the origin of the fitness cost of HGT may uncover strategies for fighting the acquisition of antibiotic resistance by gene transfer. One of the components of fitness cost is the integration of acquired genes in existing regulatory networks. ${ }^{3,4}$ This cost grows roughly with the square of the total number of genes (old and new) when they are regulated as a single pool. ${ }^{5}$ However, when HGT and core genes are regulated independently, the fitness cost is significantly reduced.

Enterobacterial species have developed precisely this strategy through at least two independent mechanisms related to the H-NS protein. H-NS is an abundant nucleoidassociated protein that contributes to DNA compaction and acts as a global regulator of the expression of a large number of genes in Gram-negative bacteria. ${ }^{6}$ Around $5 \%$ of the genes of Escherichia coli are modulated by H-NS. ${ }^{7} \mathrm{H}-\mathrm{NS}$ also plays a key role in silencing externally acquired (xenogeneic) DNA, ${ }^{8-11}$ including the major virulence genes of pathogenic E. coli, Salmonella, Shigella and Yersinia, ${ }^{11,12}$ among others.

H-NS-like proteins are not encoded only in the bacterial chromosome. Several conjugative plasmids also encode H-NS homologues. Baños et al. demonstrated that chromosomal and plasmidic H-NS proteins have distinct functional properties. ${ }^{13}$ The $\mathrm{H}-$ NS variant encoded in the IncHI plasmid R27 $\left(\mathrm{H}-\mathrm{NS}_{\mathrm{R} 27}\right)$ rescued the phenotype of a 
Salmonella mutant lacking chromosomal H-NS $\left(\mathrm{H}_{-} \mathrm{NS}_{\mathrm{C}}\right)$ for HGT genes but had no effect on most of the core genes. Furthermore, they showed that the set of genes regulated by $\mathrm{H}-\mathrm{NS}_{\mathrm{R} 27}$ coincided mostly with those that required a co-regulator of the $\mathrm{Hha} / \mathrm{YmoA}$ family for proper silencing by $\mathrm{H}_{-} \mathrm{NS}_{\mathrm{C}}$. The presence of two redundant mechanisms for the same function suggests that selective regulation of genes acquired through HGT confers a significant evolutionary advantage.

Here we describe a systematic study aiming to identify the key structural elements responsible for the distinct DNA binding and regulatory properties of Salmonella H$\mathrm{NS}_{\mathrm{C}}$ and $\mathrm{H}-\mathrm{NS}_{\mathrm{R} 27}$.

Both H-NS proteins contain an oligomerization domain and a DNA-binding domain (DBD), which are separated by a linker that is highly flexible in the absence of DNA.

Two dimerization regions connected by a long $\alpha$-helix form the oligomerization domain. The N-terminal region, including residues $1-47$, forms stable dimers. ${ }^{14}$ The second dimerization site includes residues 57-83 and was recently described by Arold et $a l$. in the crystal structure of an oligomer formed by a construct including the first 83 residues of $\mathrm{H}-N S^{15}{ }^{15}$ In the crystal structure, H-NS oligomers adopt a superhelical structure with individual H-NS molecules linked by alternating head-to-head and tail-totail dimers.

The structures of the H-NS DBDs of Salmonella and E. coli have been solved in the apo-form. ${ }^{16,17}$ The structures of the folded domains are very similar and are formed by a two stranded antiparallel $\beta$-sheet (residues 97-100 and 105-109 -residue numbers refer to Salmonella H-NS-), a $\alpha$-helical segment (residues 117-126) and a short 310 helix (residues 130-133).

A DNA complex of the DBD of Ler, a member of the H-NS family, has recently been described. ${ }^{18}$ Analysis of the complex and an extensive series of Ler and H-NS mutants demonstrated that the isolated Ler and H-NS DBDs recognize specific distortions in the minor groove of DNA that deviate from the canonical B DNA form. ${ }^{16,18-20}$ Thus, the recognition of target DNA by individual H-NS molecules follows an indirect readout model. The affinity of the isolated DBD of Ler and H-NS was shown to be rather low. However, DNA binding involves H-NS oligomers in which the cooperative binding of multiple DBDs increases affinity. ${ }^{21}$ While the interaction of individual H-NS molecules involves short DNA stretches and is sensitive to local DNA distortions, the interaction between H-NS oligomers and DNA has the potential to sense DNA on a longer length scale. This sensing capacity thus enables the recognition of general features that could 
allow the distinction between broad DNA classes that may be associated with core or HGT genes. We hypothesized that specific DNA recognition depends on the spatial arrangement of DBDs along the oligomer, constrained by the oligomer's structure, which should be compatible with the shape of the DNA region to which they bind. Thus, allosteric interplay between oligomerization and DNA binding, potentially modulated by the linker region, may provide a mechanism for long-range indirect readout of broad DNA classes.

The distinct specificity of $\mathrm{H}-\mathrm{NS}_{\mathrm{C}}$ and $\mathrm{H}-\mathrm{NS}_{\mathrm{R} 27}$ provides an opportunity to test this hypothesis. With this in mind, we prepared chimeras combining domains from the two H-NS variants, measured their DNA binding characteristics, and compared them with the two natural H-NS forms. We further refined our analysis by zooming in on specific regions and exploring point mutations in the linker region shown to be a main locus for the differences observed between $\mathrm{H}-\mathrm{NS}_{\mathrm{C}}$ and $\mathrm{H}-\mathrm{NS} \mathrm{R}_{\mathrm{R} 27}$.

\section{Results}

\section{Protein chimeras combining $\mathrm{H}-\mathrm{NS}_{\mathrm{C}}$ and $\mathrm{H}-\mathrm{NS}_{\mathrm{R} 27}$}

The amino acid sequences of $\mathrm{H}-\mathrm{NS}_{\mathrm{C}}$ and $\mathrm{H}-\mathrm{NS}_{\mathrm{R} 27}$ are shown in Fig. 1a. The secondary structure elements observed in the truncated constructs of chromosomal H-NS are indicated. Sequence differences between the two variants are concentrated mostly in the H3 helix of the oligomerization domain $(\mathbf{O} / \mathbf{o})$, the linker region $(\mathbf{L} / \mathbf{l})$, and the $\alpha$-helix of the DBD $(\mathbf{D} / \mathbf{d})$. Capital letters refer to the domains of $\mathrm{H}_{-N S_{\mathrm{C}}}$ and small letters to those of $\mathrm{H}-\mathrm{NS}_{\mathrm{R} 27}$. Four chimeras were prepared (Figure 1b). Chimera $\alpha(\mathbf{o L D})$ contained the oligomerization domain of $\mathrm{H}-\mathrm{NS}_{\mathrm{R} 27}$ and the linker region and $\mathrm{DBD}$ of $\mathrm{H}-\mathrm{NS}_{\mathrm{C}}$. Chimera $\beta$ (Old) had the complementary arrangement (oligomerization domain of $\mathrm{H}-\mathrm{NS}_{\mathrm{C}}$ and linker region and DBD of $\left.\mathrm{H}-\mathrm{NS}_{\mathrm{R} 27}\right)$. Chimera $\gamma(\mathbf{O I D})$ contained the linker region of $\mathrm{H}-$ $\mathrm{NS}_{\mathrm{R} 27}$ connecting the oligomerization domain and DBD of $\mathrm{H}-\mathrm{NS}_{\mathrm{C}}$. Finally, chimera $\delta$ (oLd) had the linker region of $\mathrm{H}-\mathrm{NS}_{\mathrm{C}}$ in the context of the oligomerization domain and DBD of $\mathrm{H}-\mathrm{NS}_{\mathrm{R} 27}$.

DNA binding was studied by Electrophoretic Mobility Shift Assays (EMSA) using a 540-bp fragment (proU ${ }_{540}$ ) containing the regulatory region of the proU promoter. The interaction of proU, a representative core gene, with $\mathrm{H}-\mathrm{NS}$ has been extensively 


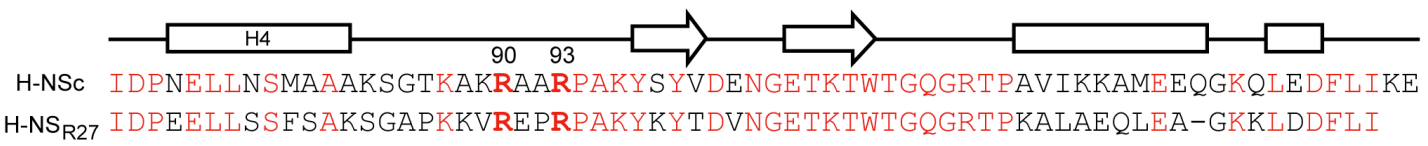

(b)
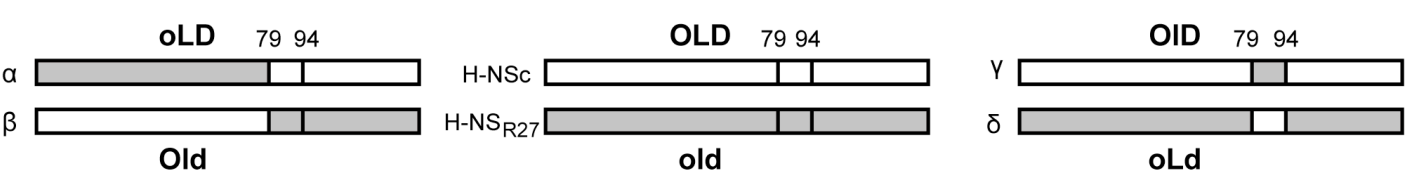

(c)
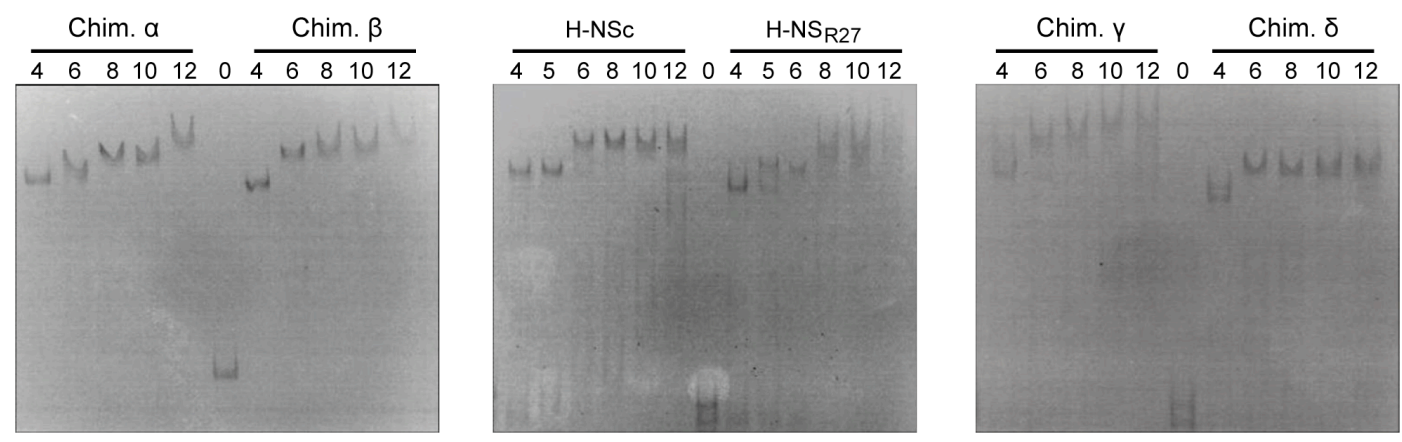

Fig. 1. Comparison of $H-N S_{C}, H-N S_{R 27}$ and chimera proteins. (a) Sequence alignment of the H-

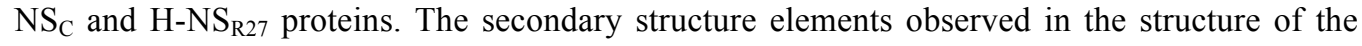
oligomerization (PDB 3NR7) and DNA-binding (PDB 2LB3) domains of Salmonella $\mathrm{H}-\mathrm{NS}_{\mathrm{C}}$ are indicated by boxes ( $\alpha$-helix) and arrows ( $\beta$-sheet). The oligomerization domain is formed by helices H1-H4. Unlabelled secondary structure elements correspond to the DNA-binding domain. The unstructured intermediate region is the linker region starting at residues 83 . Arginine residues 91 and 93 are shown in bold. (b) The chimeric proteins combined the oligomerization $(\mathrm{O} / \mathrm{o})$, linker (L/l) and DNA-binding domains $(\mathrm{D} / \mathrm{d})$ of the natural H-NS variants. Capital letters refer to the chromosomic protein and small letters to the plasmidic form. The linker region actually swapped in the chimera proteins started at residue 79 and included the last residues of helix $\mathrm{H} 4$ that are different in $\mathrm{H}-\mathrm{NS}_{\mathrm{C}}$ and $\mathrm{H}-\mathrm{NS}_{\mathrm{R} 27}$ proteins. (c) Effect of increasing amounts of $\mathrm{H}-\mathrm{NS}_{\mathrm{C}}$ and $\mathrm{H}-\mathrm{NS}_{\mathrm{R} 27}$ (central panel) and chimeric $\mathrm{H}-\mathrm{NS}_{\mathrm{C}}-\mathrm{H}-\mathrm{NS}_{\mathrm{R} 27}$ proteins (left and right panels) on the electrophoretic mobility of a 540-bp fragment (proU $\mathrm{U}_{540}$ ) containing the regulatory region of the $p r o U$ promoter. Protein concentrations $(\mu \mathrm{M})$ are indicated above each line.

studied. $^{21,22}$ In a previous transcriptomic analysis, proU was insensitive to $\mathrm{H}_{-\mathrm{NS}} \mathrm{R}_{27}$ modulation. $^{13}$

Fig. 1c compares the electrophoretic mobility of complexes formed by proU $_{540}$ with increasing concentrations of $\mathrm{H}-\mathrm{NS}_{\mathrm{C}}$ and $\mathrm{H}-\mathrm{NS}_{\mathrm{R} 27}$. Below $12 \mu \mathrm{M}, \mathrm{H}-\mathrm{NS}_{\mathrm{C}}$ caused the successive appearance of two distinct bands, corresponding to complexes of decreasing 
mobility with a rather sharp transition between them. In contrast, $\mathrm{H}-\mathrm{NS} \mathrm{R}_{\mathrm{R} 27}$ induced the appearance of a first band of similar mobility to the one observed with $\mathrm{H}_{-} \mathrm{NS}_{\mathrm{C}}$; however, as the protein concentration was increased, more than one band with decreasing mobility appeared but faded away at high concentrations, suggesting a variation in the DNA complexation pattern with respect to $\mathrm{H}_{-} \mathrm{NS}_{\mathrm{C}}$.

Chimeras $\alpha$ and $\beta$, containing the linker region and C-terminal domain of $\mathrm{H}-\mathrm{NS}_{\mathrm{C}}$ and $\mathrm{H}-$ $\mathrm{NS}_{\mathrm{R} 27}$, respectively, showed distinct EMSA patterns. The pattern caused by chimera $\beta$ (Old) was similar to that observed with $\mathrm{H}-\mathrm{NS}_{\mathrm{R} 27}$, with the characteristic smearing of the most retarded band as the protein concentration increased. In contrast, the EMSA pattern caused by chimera $\alpha(\mathbf{O L D})$ was more reminiscent of the one caused by $\mathrm{H}-\mathrm{NS} \mathrm{C}_{\mathrm{C}}$, with sharp bands for the second complex until $10 \mu \mathrm{M}$ of protein. As for $\mathrm{H}_{-\mathrm{NS}}$,7, bands of intermediate mobility were also observed in this case.

A more striking result was observed when chimeras $\gamma(\mathbf{O I D})$ and $\delta(\mathbf{o L d})$, in which only the linker regions were exchanged, were compared. The chimera containing only the linker region of $\mathrm{H}_{-} \mathrm{NS}_{\mathrm{R} 27}$ showed an EMSA pattern strongly reminiscent of $\mathrm{H}_{-}-\mathrm{NS}_{\mathrm{R} 27}$, in spite of the fact that $87 \%$ of the sequence is identical to that of $\mathrm{H}_{-}-\mathrm{NS}_{\mathrm{C}}$. Consistently, the chimera containing only the linker region from $\mathrm{H}_{-} \mathrm{NS}_{\mathrm{C}}$ showed a pattern with two welldefined retarded bands that appeared as the protein concentration increased, matching the one observed with $\mathrm{H}_{-\mathrm{NS}}$. However, the mobility of the two bands corresponding to DNA complexes with chimera $\delta$ was higher than those corresponding to the complexes with $\mathrm{H}-\mathrm{NS}$.

These results show that the flexible linker connecting the oligomerization domain and DBD of H-NS proteins has a strong influence on the electrophoretic behavior of the DNA complexes formed by the protein and that the linker regions of $\mathrm{H}_{-}-\mathrm{NS}_{\mathrm{C}}$ and $\mathrm{H}-$ $\mathrm{NS}_{\mathrm{R} 27}$ are not functionally equivalent.

\section{NMR analysis of truncated constructs containing the C-terminal domain.}

Previous reports ${ }^{18,23}$ suggested that the linker region close to the DBD of H-NS or Ler interacts with DNA. On the other hand, the linker is highly flexible in the absence of DNA. NMR spectra of full length $\mathrm{H}_{-} \mathrm{NS}_{\mathrm{C}}{ }^{24}$ or $\mathrm{H}_{-\mathrm{NS}} \mathrm{R}_{27}$ (Supplementary Fig. 1) are 
almost superimposable to those obtained for the isolated DBD. This finding suggests that in the absence of DNA the DBD reorients freely with respect to the much more rigid oligomer, which is not observable by liquid state NMR.

In order to study the involvement of the linker region in DNA binding independently of the oligomerization process, we examined three truncated forms of $\mathrm{H}-\mathrm{NS} \mathrm{C}_{\mathrm{C}}$ and $\mathrm{H}-\mathrm{NS}_{\mathrm{R} 27}$, including variable portions of the linker attached to the folded DBD.

The smallest fragments, formed by residues 95-137 of $\mathrm{H}_{-\mathrm{NS}}\left(\mathrm{H}-\mathrm{NS} \mathrm{S}_{9 \mathrm{C}}\right)$ or $95-134$ of $\mathrm{H}_{-N S_{\mathrm{R} 27}}\left(\mathrm{H}-\mathrm{NS}_{95 \mathrm{R}}\right)$, contained exclusively the structured C-terminal domain. The other fragments started at residue $87\left(\mathrm{H}_{-} \mathrm{NS}_{87 \mathrm{C}}, \mathrm{H}-\mathrm{NS} \mathrm{S}_{87 \mathrm{R}}\right)$ or $81\left(\mathrm{H}-\mathrm{NS}_{81 \mathrm{C}}, \mathrm{H}-\mathrm{NS}_{81 \mathrm{R}}\right)$ and finished at residue 137 or 134 for the chromosomal and plasmidic constructs, respectively.

DNA binding was studied by NMR, comparing the chemical shift changes caused by the addition of a 23-bp sequence from the hilA promoter (hilA 23$)$. This DNA segment belongs to a HGT fragment and includes $6 \mathrm{bp}$ of the high affinity motif identified by Bouffartigues et al. ${ }^{21}$

Addition of 1 equivalent of hilA ${ }_{23}$ induced only minor changes in the ${ }^{1} \mathrm{H}^{-}{ }^{15} \mathrm{~N}$ HSQC spectra of the constructs that contained only the structured C-terminal domain of either H-NS variant. However, and consistent with previous studies, ${ }^{16,19,23}$ the same amount of DNA produced massive changes in the ${ }^{1} \mathrm{H}_{-}{ }^{15} \mathrm{~N}$ HSQC spectra of the fragments of the two proteins that partially or completely included the linker region (Supplementary Fig. $2,3)$. 
(a)

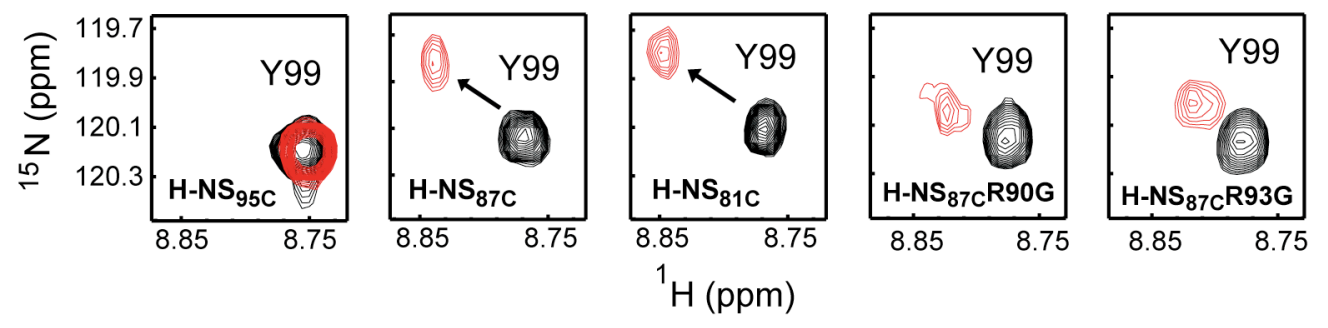

(b)
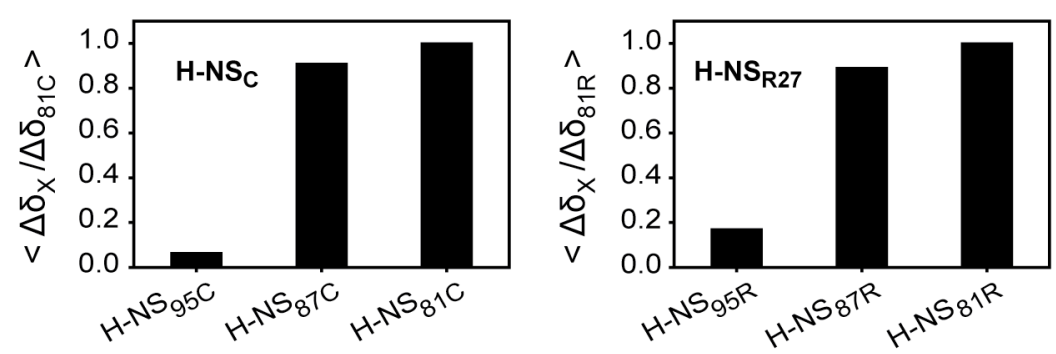

(c)
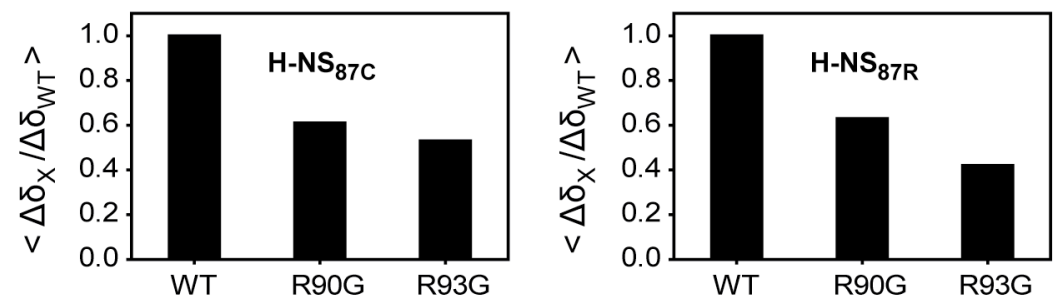

Fig. 2. $H-N S_{C}$ and $H-N S_{R 27}$ linker residues contribute to DNA binding. (a) Expansions of ${ }^{1} \mathrm{H}-{ }^{15} \mathrm{~N}$ NMR HSQC spectra of H-NS ${ }_{95 \mathrm{C}}, \mathrm{H}-\mathrm{NS}_{87 \mathrm{C}}, \mathrm{H}-\mathrm{NS}_{81 \mathrm{C}}, \mathrm{H}-\mathrm{NS}_{87 \mathrm{C}} \mathrm{R} 90 \mathrm{G}$ and $\mathrm{H}-\mathrm{NS}_{87 \mathrm{C}} \mathrm{R} 93 \mathrm{G}$ in the absence (black) and in the presence of 1 equivalent of hil $\mathrm{A}_{23}$ (red) illustrating the DNA-induced chemical shift variations. (b) Relative values of the average combined backbone amide chemical shifts induced by the presence of 1 equivalent of hil $\mathrm{A}_{23}$ in $\mathrm{H}-\mathrm{NS}_{95 \mathrm{C}}, \mathrm{H}-\mathrm{NS}_{87 \mathrm{C}}$ and $\mathrm{H}-\mathrm{NS}_{81 \mathrm{C}}$ (left panel) and $\mathrm{H}_{-\mathrm{NS}} \mathrm{S}_{9 \mathrm{R}}, \mathrm{H}-\mathrm{NS}_{87 \mathrm{R}}$ and $\mathrm{H}-\mathrm{NS}_{81 \mathrm{R}}$ (right panel). Combined ${ }^{1} \mathrm{H}$ and ${ }^{15} \mathrm{~N}$ chemical shift changes are calculated as $\left.\Delta \delta=\left[\delta_{\mathrm{HN}}{ }^{2}+\left(\Phi \cdot \delta_{\mathrm{N}}\right)^{2}\right]^{1 / 2}\right)$, where $\Phi$ corresponds to the ratio of ${ }^{15} \mathrm{~N}$ and ${ }^{1} \mathrm{H}$ magnetogyric constants. The average was taken over the seven signals showing the largest chemical shift changes and that could be unambiguously measured in all variants of each protein.

Figure 2a shows expansions of a well-resolved cross peak in the ${ }^{1} \mathrm{H}^{15}{ }^{15} \mathrm{HSQC}$ spectra of $\mathrm{H}_{-\mathrm{NS}} \mathrm{S}_{5 \mathrm{C}}, \mathrm{H}-\mathrm{NS}_{87 \mathrm{C}}$, and $\mathrm{H}-\mathrm{NS}_{81 \mathrm{C}}$, in the absence and in the presence of 1 equivalent of hilA $A_{23}$. Fig. $2 b$ shows the average DNA-induced shifts of the NH signals of the seven residues showing the largest chemical shifts variations, relative to those observed in the longer fragment of the chromosomal $\left(\mathrm{H}-\mathrm{NS}_{81 \mathrm{C}}\right)$ and plasmidic $\left(\mathrm{H}-\mathrm{NS}_{81 \mathrm{R}}\right)$ constructs. 
These data indicate that the structured C-terminal domain is not sufficient for tight binding to DNA and that extra residues from the preceding linker are required to strengthen the interaction. The perturbations induced by the presence of DNA in the NMR spectra of $\mathrm{H}-\mathrm{NS}_{81 \mathrm{C}}$ and $\mathrm{H}-\mathrm{NS}_{87 \mathrm{C}}$ or $\mathrm{H}-\mathrm{NS}_{81 \mathrm{R}}$ and $\mathrm{H}-\mathrm{NS} \mathrm{S}_{87 \mathrm{R}}$ were very similar, thereby suggesting that residues contributing to the stability of the complex with the isolated H-NS constructs are located in the 87-94 segment.

The dissociation constant estimated from a titration of $\mathrm{H}_{-\mathrm{NS}} \mathrm{S}_{87 \mathrm{R}}$ with hil $\mathrm{A}_{23}$ (Supplementary Fig. 4) was $\sim 2 \mu \mathrm{M}$, a value similar to those reported by several authors $^{16,19}$ for the interactions between equivalent chromosomal H-NS constructs and several dsDNA sequences of similar length.

Two arginine residues, Arg 90 and Arg 93, in the 87-94 segment are highly conserved in the amino acid sequence of H-NS proteins. Arginine residues are often involved in electrostatic interactions with DNA. An arginine residue in the folded domains of Ler and H-NS was found to be essential for the recognition of minor groove distortions. ${ }^{18}$ To evaluate the potential role of these residues in DNA binding, they were individually mutated to Gly in the two H-NS proteins. Expansions of the ${ }^{1} \mathrm{H}-{ }^{15} \mathrm{~N}$ HSQC spectra of the $\mathrm{H}-\mathrm{NS}_{87 \mathrm{C}} \mathrm{R} 90 \mathrm{G}$ and $\mathrm{H}-\mathrm{NS}_{87 \mathrm{C}} \mathrm{R} 93 \mathrm{G}$ mutants in the absence and presence of 1 equivalent of hil $\mathrm{A}_{23}$ are shown in Fig. 2a and the average DNA-induced shift of the most affected peaks is shown in Fig. 2c. Both arginine residues were found to contribute to DNA binding. Arg 93 appeared to have a slightly higher contribution, consistent with being closer to the structured DNA-binding domain.

Binding to two other dsDNA fragments of $\mathrm{H}-\mathrm{NS}_{87 \mathrm{C}}, \mathrm{H}-\mathrm{NS}_{87 \mathrm{R}}$ and single arginine mutants of the two constructs was compared with that to hilA $\mathrm{A}_{23}$ using the NMR shifts induced by a single addition of the corresponding double stranded nucleotide. The dsDNA fragments used were a 26-bp segment found in the proU regulatory region, centred in the H-NS high affinity motif identified by Bouffartigues et al. $\left(\text { proU }_{26}\right)^{21}$, and a 10-bp fragment $\left(\mathrm{AATT}_{10}\right)$ previously used for the structure determination of the $\mathrm{C}$ terminal domain of Ler in complex with DNA. ${ }^{18}$ No significant differences were observed between the relative average shifts per base pair induced by each dsDNA fragment in the two constructs with the wild-type sequences (Supplementary Fig. 5 and Supplementary Fig. 6). Mutations in Arg 93 had a more pronounced effect on the interaction with the $\mathrm{AATT}_{10}$ fragment. This finding could be attributed to the more specific interaction of the folded domain with the $\mathrm{AATT}_{10}$ sequence, placing the nearby 
arginine residues close to DNA. In the longer sequences, dynamic exchange between several sites may tend to equalize the contribution of the two arginine residues.

\section{DNA binding of R90G and R93G mutants of full-length H-NS}

Since DNA binding and H-NS oligomerization take place simultaneously and presumably influence each other, we studied the effect of mutations in the linker domain of full-length $\mathrm{H}-\mathrm{NS}_{\mathrm{C}}$ and $\mathrm{H}-\mathrm{NS}_{\mathrm{R} 27}$ on DNA binding. In the absence of DNA all full-length H-NS variants studied showed very similar oligomerization behavior, as seen by analytical size exclusion chromatography. Chromatography profiles of $\mathrm{H}_{-} \mathrm{NS}_{\mathrm{C}}, \mathrm{H}-$ $\mathrm{NS}_{\mathrm{R} 27}$, chimera $\gamma$, and chimera $\delta$ are shown in supplementary Figure 7. Compared to protein standards, the apparent size of oligomers formed by $\mathrm{H}-\mathrm{NS}_{\mathrm{C}}$ and chimera $\delta$ is 5.4 monomers, and that of $\mathrm{NS}_{\mathrm{R} 27}$ and chimera $\gamma$ oligomers, is 6.0 units. As the nucleoprotein complexes containing oligomeric H-NS are not visible by NMR, we used EMSA experiments under identical conditions to those applied to study H-NS chimeras.
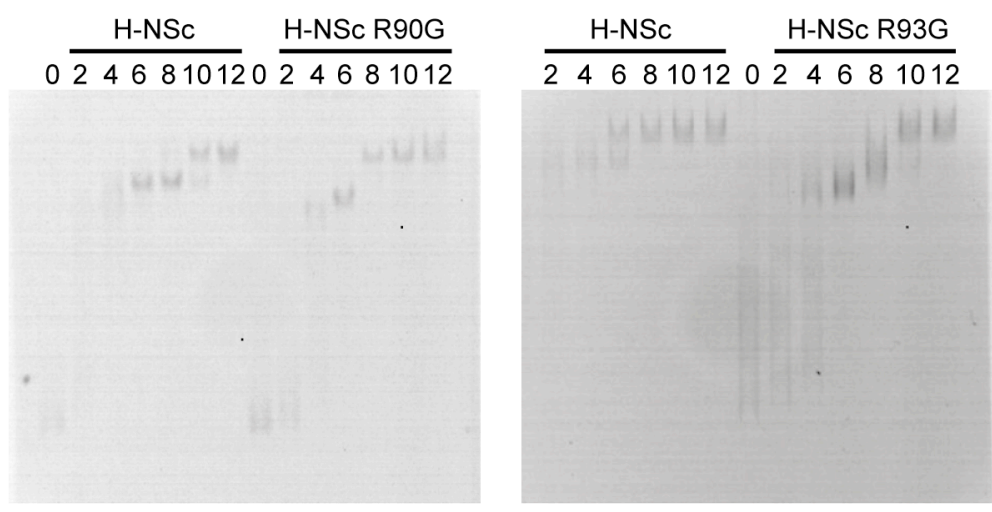

(b)

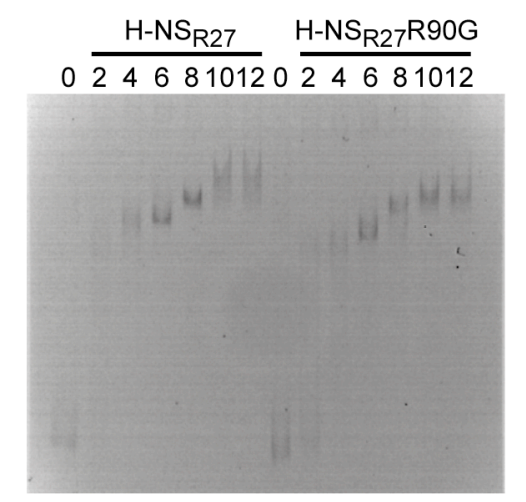
$0 \frac{\mathrm{H}-\mathrm{NS}_{\mathrm{R} 27}}{24681012} 0 \frac{\mathrm{H}-\mathrm{NS}_{\mathrm{R} 27} \mathrm{R} 93 \mathrm{G}}{24681012}$

Fig. 3. DNA binding by R90G and R93G mutants of full-length $H-N S_{C}$ and $H-N S_{R 27}$. EMSA of proU $\mathrm{U}_{540}$ in the presence of increasing amounts of wild-type and mutant $\mathrm{H}-\mathrm{NS}_{\mathrm{C}}$ (a) and $\mathrm{H}_{-} \mathrm{NS}_{\mathrm{R} 27}$ (b) proteins. The protein concentrations are indicated $(\mu \mathrm{M})$. 
Fig. 3 compares the retardation of the DNA bands with increasing concentrations of wild-type, R90G and R93G mutants of the two H-NS variants. Both mutants showed higher mobility of the first retarded band observed at low protein concentrations, suggesting a lower DNA affinity than the wild-type proteins. This observation is consistent with the reduced interaction observed when the same mutations were introduced in a monomeric truncated construct and studied by NMR.

In contrast, the band formed at intermediate concentrations appeared at similar or even lower protein concentrations in the case of R90G and displayed similar mobility. These results suggest that the stability of the initial DNA-H-NS complexes formed at low protein concentrations is strongly dependent on the intrinsic DNA binding affinity of the individual H-NS molecules. However, the stability of the nucleoprotein complex contributing to the second band was dominated by the capacity of several binding domains to simultaneously interact with DNA and small differences in the binding affinity of individual H-NS molecules becomes negligible. In fact, a slightly looser binding by each individual molecule, in the case of the R90G mutant, may facilitate the simultaneous interaction of several H-NS molecules.

Allowing additional flexibility to the linker may facilitate the simultaneous optimization of several DNA-protein interactions involving H-NS molecules that are connected through their oligomerization domains.

\section{Effect of mutations at positions 91- 93 of $\mathrm{H}-\mathrm{NS} \mathrm{C}_{\mathrm{C}}$}

The two residues separating the conserved arginines at positions 90 and 93 are Ala-Ala in $\mathrm{H}_{-} \mathrm{NS}_{\mathrm{C}}$ and Glu-Pro in $\mathrm{H}-\mathrm{NS}_{\mathrm{R} 27}$. These non-conservative replacements may affect the charge and the flexibility of the linker. Using EMSA, we characterized the DNA binding of four $\mathrm{H}_{-\mathrm{NS}}$ mutants in the 91-93 positions: a double mutant A91E/A92P (REPR), two single mutants A91E (REAR) and A92P (RAPR), and a triple mutant A91E/A92P/R93G (REPG). The RAPR mutant retains the charge of wild-type $\mathrm{H}-N S_{C}$,

while the REPR and REAR mutants have a charge difference of -1 , and the REPG mutant -2 , respectively, with respect to wild-type $\mathrm{H}-\mathrm{NS}_{\mathrm{C}}$. 
(a)
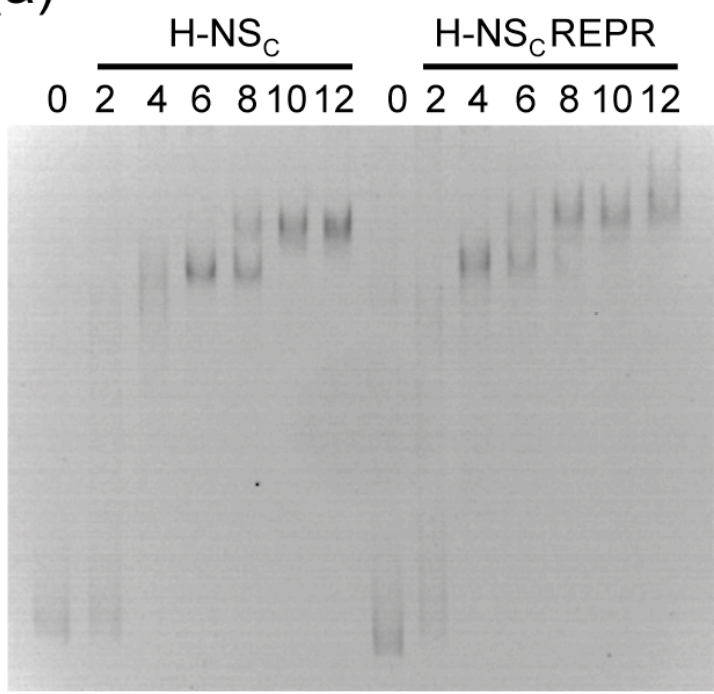

(c)

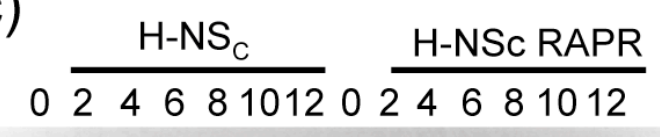

(b)
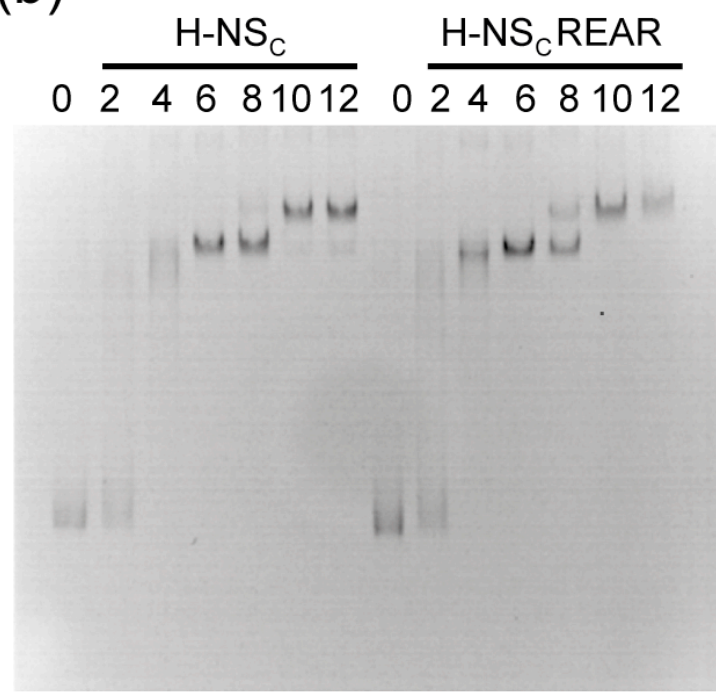

(d)

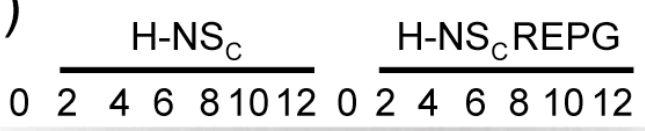

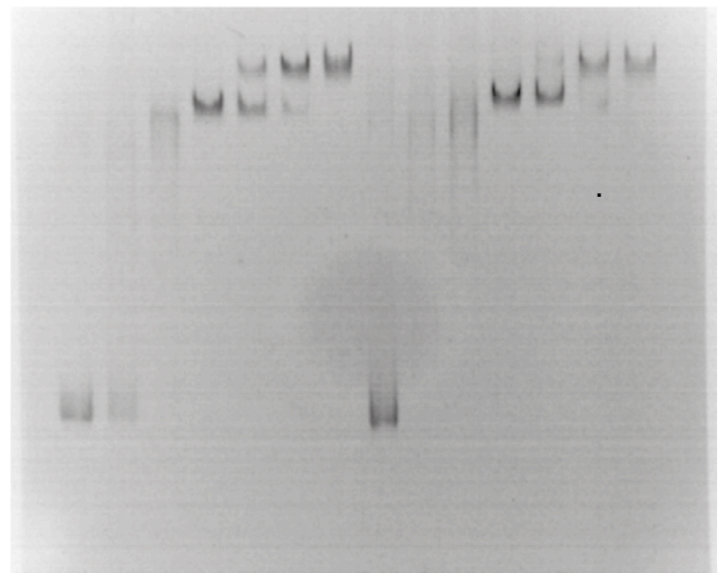

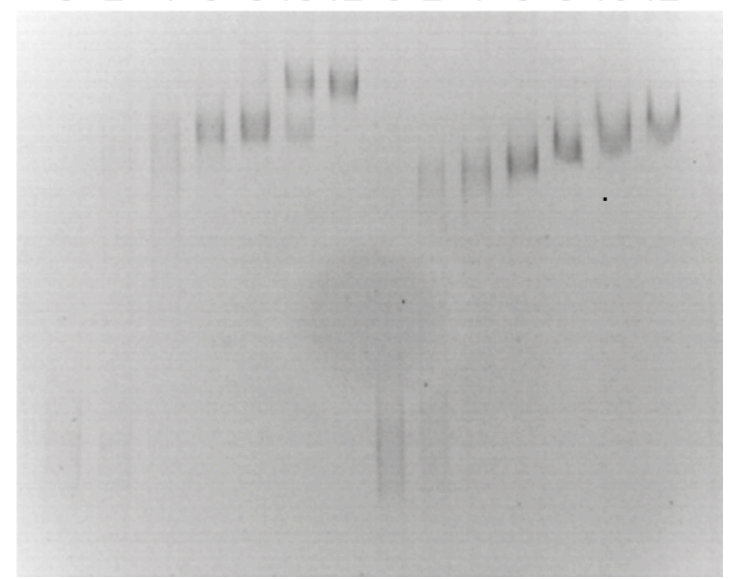

Fig. 4. DNA binding by $H-N S_{R 27}$-inspired linker mutants of full-length $H-N S_{C}$ at low protein concentrations. EMSA of proU ${ }_{540}$ in the presence of wild-type $\mathrm{H}-\mathrm{NS}_{\mathrm{C}}$ and REPR (a), REAR (b), RAPR (c) and REPG (d) H-NS $\mathrm{C}_{\mathrm{C}}$ mutants at the indicated concentrations up to $12 \mu \mathrm{M}$.

Fig. 4 shows the changes in electrophoretic mobility of the proU $U_{540}$ DNA fragment induced by the four mutants at protein concentrations below $12 \mu \mathrm{M}$. No significant

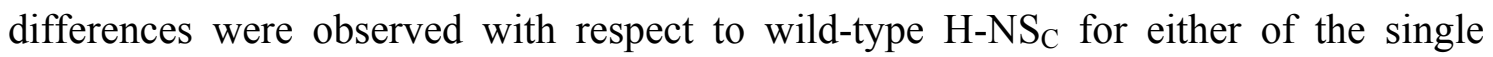
mutants or for the double mutant. However, the triple mutant caused significantly lower DNA retardation (Fig. 4d), thereby indicating that it has a substantially lower affinity for DNA than the wild-type protein or the other mutants studied.

For the mutants that showed similar EMSA patterns up to a protein concentration of 12 $\mu \mathrm{M}$, we explored the retardation effects at concentrations up to $40 \mu \mathrm{M}$ (Fig. 5). 
(a)

$0 \frac{\mathrm{H}-\mathrm{NS}_{\mathrm{C}}}{68101214161820253040}$

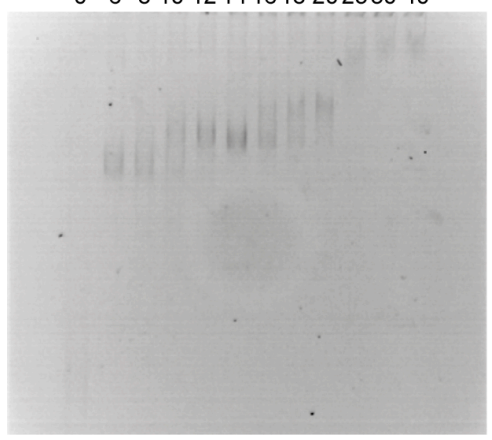

(b)

$\frac{H-N S_{C} \text { REPR }}{268101214161820253040}$ (c)

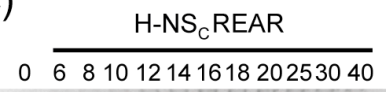

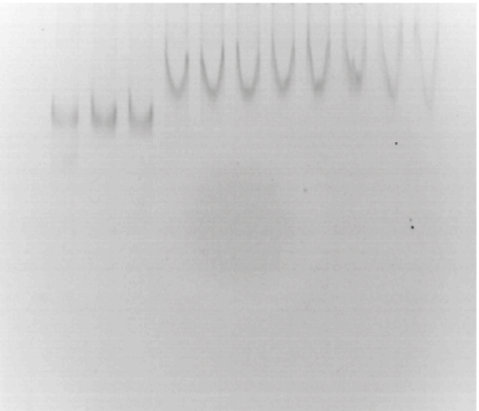

Fig. 5. Single mutations at positions 91 or 92 of full-length $H-N S_{C}$ affect the formation of high order nucleoprotein complexes. EMSA of pro $\mathrm{U}_{540}$ in the presence of increasing concentrations $(6,8,10,12,14$,

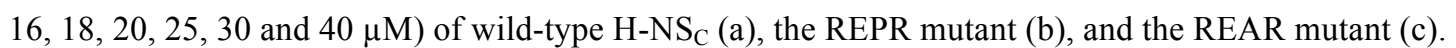

Fig. 5a shows the effect of increasing concentrations of $\mathrm{H}-\mathrm{NS}_{\mathrm{C}}$ on $\operatorname{proU}_{540}$ mobility. Following the trend observed at lower concentrations, new discrete bands were observed. This observation suggests the formation of additional nucleoprotein complexes, presumably involving larger H-NS oligomers and/or other geometries. In contrast, the REPR double mutant did not induce the formation of additional complexes, and a single band with constant electrophoretic mobility was observed between $12 \mu \mathrm{M}$ and $40 \mu \mathrm{M}$ of protein (Fig. 5b). The REAR mutant showed an intermediate behaviour between that of wild- type $\mathrm{H}_{-N S}$ (with the sequence ${ }^{90} \mathrm{RAAR}^{93}$ ) and the REPR mutant (Fig. 5c): at concentrations higher than $12 \mu \mathrm{M}$, we observed a continuous decrease in electrophoretic mobility but not the discrete changes observed in the wild-type protein. Finally, at higher protein concentrations, the RAPR mutant resulted in the formation of high molecular weight complexes or aggregates, which failed to enter the gel. Interestingly, high concentrations of wild-type $\mathrm{H}_{-} \mathrm{NS}_{\mathrm{R} 27}$ in the presence of $\operatorname{proU}_{540}$ also resulted in the formation of complexes; however, these could not be characterized because they did not enter the gel (Supplementary Fig. 8). 


\section{Discussion}

The $\mathrm{H}-\mathrm{NS}_{\mathrm{C}}$ protein, encoded in the main chromosome of Salmonella, is a general regulator of gene expression and shows broad specificity, including core as well as horizontally acquired genes. In contrast, the $\mathrm{H}_{-} \mathrm{NS}_{\mathrm{R} 27}$ variant, encoded in the $\mathrm{R} 27$ plasmid, shows selectivity for horizontally acquired genes in vivo.

The residues that are not conserved between $\mathrm{H}-\mathrm{NS}_{\mathrm{C}}$ and $\mathrm{H}-\mathrm{NS}_{\mathrm{R} 27}$ are concentrated mainly in three clusters located in each of the two structured domains (oligomerization domain and DBD) and in the linker region connecting them. To better understand the basis of the differential selectivity exhibited by $\mathrm{H}_{-} \mathrm{NS}_{\mathrm{C}}$ and $\mathrm{H}-\mathrm{NS}_{\mathrm{R} 27}$, we used EMSAs to compare the DNA binding properties of the two H-NS variants, as well as protein chimeras containing contributions from the two natural proteins. The proU $\mathrm{U}_{540}$ DNA fragment chosen included the regulatory region of the proU promoter, a wellcharacterized core gene that contains a validated high affinity site for H-NS. ${ }^{21}$ Under our experimental conditions, both $\mathrm{H}_{-} \mathrm{NS}_{\mathrm{C}}$ and $\mathrm{H}-\mathrm{NS}_{\mathrm{R} 27}$ interacted with proU $\mathrm{U}_{540}$, causing a significant reduction in its electrophoretic mobility. However, the appearance of successive nucleoprotein complexes at increasing protein concentrations and the mobility of the corresponding bands resulted in distinct EMSA patterns for the two wild-type proteins.

The EMSA profiles of the chimera proteins in which the linker region and DBD of one of the natural H-NS variants were combined with the oligomerization domain of the other resembled that of the variant contributing the DBD and linker domains. This observation thus suggests that the linker region contributes to the distinct DNA binding properties shown by $\mathrm{H}-\mathrm{NS}_{\mathrm{C}}$ and $\mathrm{H}-\mathrm{NS}_{\mathrm{R} 27}$ originate in these two regions of the proteins. To differentiate between the DBD and the linker, we studied chimeras in which only the linker domain of one H-NS variant was introduced linking the oligomerization domain and DBD of the other form. These chimeras showed EMSA profiles characteristic of the variant contributing the linker domain (Fig. 1). This striking result suggests that the linker is a major determinant of the distinct DNA binding specificity of $\mathrm{H}_{-} \mathrm{NS}_{\mathrm{C}}$ and $\mathrm{H}-$ $\mathrm{NS}_{\mathrm{R} 27}$ and strongly points to the interplay between $\mathrm{H}-\mathrm{NS}$ oligomerization and DNA binding as a key contribution to the variations in selectivity observed between the two forms in vivo. 
In order to experimentally decouple DNA binding and oligomerization, we used NMR to study truncated forms of $\mathrm{H}-\mathrm{NS}_{\mathrm{C}}$ and $\mathrm{H}-\mathrm{NS}_{\mathrm{R} 27}$ lacking the oligomerization domain but including the DBD as well as variable portions of the corresponding linker.

The bare DBD, including only the folded region starting at residue 95 without any residue from the linker, had a very low affinity for DNA (Fig. 2). Although the DBD contains essential residues for DNA binding and the recognition of minor groove distortions that constitute the local recognition code, ${ }^{18}$ the contribution of charged residues belonging to the linker residue, which is unstructured in the absence of DNA, is essential. A comparison of constructs including portions of the linker and the $\mathrm{C}$ terminal structured domain showed that residues in the 87-94 region, and specifically, the conserved arginine residues at positions 90 and 93, contribute to efficient DNA binding by individual H-NS molecules.

The interaction of linker regions with DNA is expected to reduce DNA flexibility and have an effect on the connection between DNA binding and oligomerization. Therefore, we studied the effect of mutating residues in the 90-93 region of full-length $\mathrm{H}_{-\mathrm{NS}}$ using EMSA.

The EMSA patterns observed for $\mathrm{H}-\mathrm{NS}_{\mathrm{C}}$ at concentrations below $12 \mu \mathrm{M}$ show two welldefined retarded bands. We hypothesize that while the first band probably corresponds to the formation of the initial H-NS-DNA complexes, involving the binding of only a small number of H-NS molecules, the second band observed at increasing H-NS concentrations reflects the transition to complexes involving large H-NS oligomers binding cooperatively to long DNA stretches. Additional discrete bands appearing at concentrations of $\mathrm{H}_{-\mathrm{NS}}$ higher than $12 \mu \mathrm{M}$ may correspond to distinct higher order structures involving larger $\mathrm{H}_{-} \mathrm{NS}_{\mathrm{C}}$ oligomers interacting with longer DNA stretches, although not necessarily continuous given the known capacity of H-NS to bridge DNA double helical segments. ${ }^{25}$

The mutations of Arg 90 or Arg 93 to glycine in the linker region of H-NS increases the mobility of the band that first appears at lower protein concentrations (Fig. 3). The lower retardation of this band parallels the lower binding affinity of these mutants determined by NMR in truncated mutants. This observation confirms that the stability of the complexes contributing to the first retarded band depends reflects the DNA affinity of individual H-NS molecules, as would be expected for small oligomers.

However, the complex contributing to the second band was apparently unaffected by the mutation of the two arginine residues in the linker. This band was observed at similar 
protein concentrations in the wild-type and mutated forms of H-NS, thereby suggesting that binding of large oligomers depends more on the optimization of the simultaneously interaction of multiple DBD (and adjacent linkers) with DNA than on their individual affinity for DNA.

Interestingly, the concentration at which the second band was observed was lower for the R90G mutant than for the wild-type protein, suggesting that the increased flexibility of the linker resulting from the lack of interaction between Arg 90 and DNA could even facilitate the simultaneous interaction of multiple H-NS molecules and compensate for the lower affinity of the individual molecules.

The sequence variations between $\mathrm{H}-\mathrm{NS}_{\mathrm{C}}$ and $\mathrm{H}-\mathrm{NS}_{\mathrm{R} 27}$ include non-conservative replacements in the two positions flanked by the conserved Arg 90 and Arg 93 residues. Considering that these two residues interact with DNA, the intervening residues are also expected to be crucial. Replacing the two residues present at positions 91 and 92 of $\mathrm{H}-$ $\mathrm{NS}_{\mathrm{C}}$ (Ala-Ala) by those found in $\mathrm{H}_{-}-\mathrm{NS}_{\mathrm{R} 27}$ (Glu-Pro) modified the global charge of the linker, in addition to reducing its flexibility.

The introduction of the residues of $\mathrm{H}_{-\mathrm{NS}} \mathrm{R}_{27}$ at the equivalent positions 91 and 92 in wild-type $\mathrm{H}-\mathrm{NS}_{\mathrm{C}}$, the two single mutants (REAR and RAPR), and the double mutant (REPR) caused similar EMSA patterns, with two bands of similar mobility observed at concentrations below $12 \mu \mathrm{M}$ (Fig. 4). This observation contrasts with the effect of mutations of Arg 90 and Arg 93, in spite of the fact that the presence of a glutamic acid in two of the mutants also reduced the overall positive charge of the linker. Only the triple mutant, in which Arg 93 was also replaced by glycine, thus further reducing the charge of the linker, showed a clear decrease in DNA affinity.

The major effect of mutations in $\mathrm{H}-\mathrm{NS}_{\mathrm{C}}$ mimicking the variations between $\mathrm{H}-\mathrm{NS}_{\mathrm{C}}$ and $\mathrm{H}-\mathrm{NS}_{\mathrm{R} 27}$ at positions 91 and 92 were observed in the high order nucleoprotein complexes formed at protein concentrations higher than $12 \mu \mathrm{M}$.

In contrast to wild-type $\mathrm{H}-\mathrm{NS}_{\mathrm{C}}$, the REPR mutant did not form higher order complexes above $12 \mu \mathrm{M}$ (Fig. 5b). Similarly, the REAR mutant showed only a slow decrease in mobility at increasing protein concentrations. This finding suggests that the formation of higher order complexes was also impaired with respect to the wild-type protein.

Also, in contrast to wild-type $\mathrm{H}-\mathrm{NS}_{\mathrm{C}}$, at concentrations above $12 \mu \mathrm{M}$ the RAPR mutant caused the formation of DNA complexes that were too large to enter the gel, 
presumably because of extensive intermolecular interactions. A similar effect was observed at high concentrations of wild-type $\mathrm{H}_{-} \mathrm{NS}_{\mathrm{R} 27}$. The different behavior of $\mathrm{H}$ $\mathrm{NS}_{\mathrm{R} 27}$ and the REPR $\mathrm{H}-\mathrm{NS}_{\mathrm{C}}$ mutant, in spite of having the same sequence in the 90-93 region, reflects the effect of additional sequence variations elsewhere.

These results demonstrate that interactions in the 91-93 region of the H-NS linker have a strong effect on the formation of the nucleoprotein complexes that require high protein concentrations and that presumably involve large H-NS oligomers.

Changing Ala-Ala by Glu-Pro reduced the positive charge of the linker and added a rigidifying proline residue. The effect of the negatively charged residue in the presence of the two conserved arginines had little effect on the stability of the initial nucleoprotein complexes formed at low protein concentration (Fig. 4); however, it had a strong influence on the formation of complexes involving larger oligomers. We propose that the electrostatic repulsion between the negatively charged glutamic acid and DNA is relieved when this residue points away from DNA, but this constraint probably strongly restricts the flexibility of the linker.

A reduction in linker flexibility could explain the restricted formation of nucleoprotein complexes involving larger oligomers observed with wild-type $\mathrm{H}_{-} \mathrm{NS}_{\mathrm{C}}$ in the REPR and REAR mutants.

H-NS oligomers form a framework presenting an array of DBDs. Cooperative binding requires matching the shapes of the H-NS oligomer and its cognate DNA. However, as the size of the nucleoprotein complexes increases, with longer H-NS oligomers sensing longer DNA fragments, shape matching between H-NS oligomers and DNA becomes more difficult to achieve. The flexibility of the linker alleviates this problem, enabling the formation of complexes with DNA molecules displaying a variety of distortions. These may include long-range distortions of the DNA geometry along a continuous long segment or DNA geometries created by bridging distant segments.

According to this model, a reduction in linker flexibility will result in a restriction of the size and/or type of nucleoprotein complexes and an increase in selectivity (Fig. 6).

While a flexible linker may provide the minimal selectivity observed for chromosomal H-NS, which can silence both core genes and those acquired through horizontal transfer, the more rigid linker found in $\mathrm{H}-\mathrm{NS}_{\mathrm{R} 27}$ may restrict the efficient interactions of only a subset of genes associated with HGT elements. 

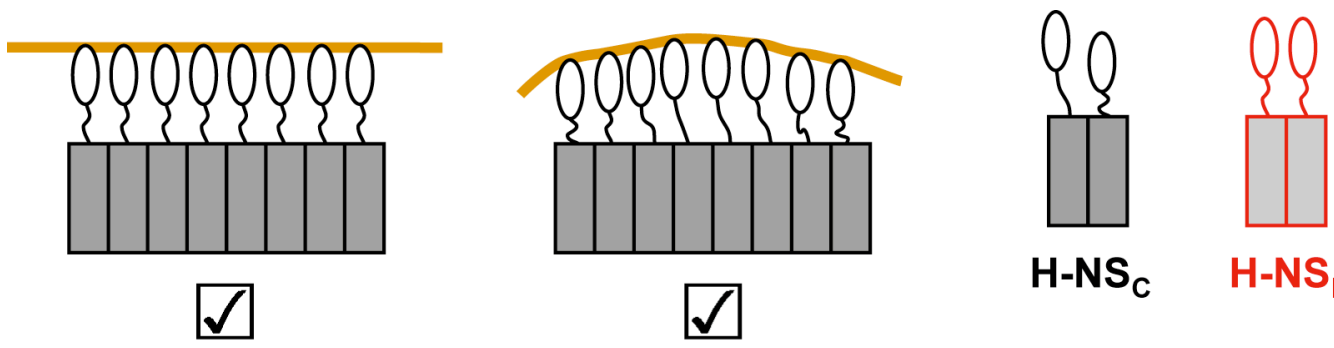

H-NS ${ }_{\mathrm{C}} \quad \mathrm{H}_{-} \mathrm{NS}_{\mathrm{R} 27}$
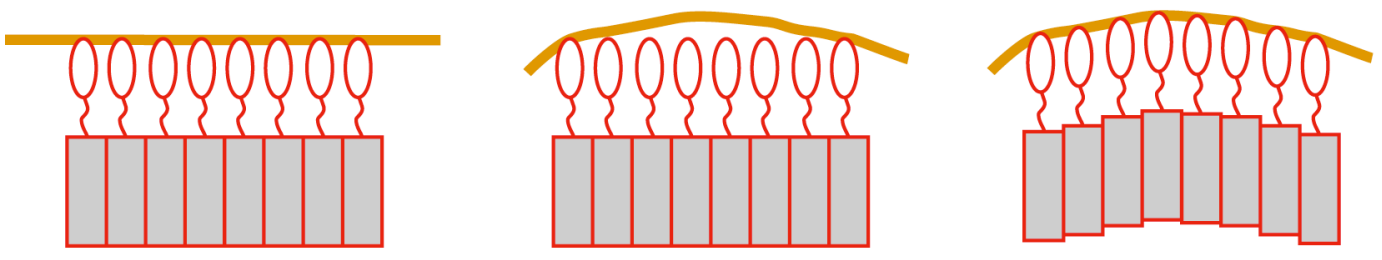

$\checkmark$
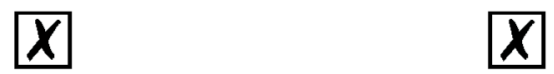

Fig. 6. Schematic model explaining the effect of linker flexibility on the selectivity of H-NS variants. The two left top panels show how the flexibility of the linker of $\mathrm{H}_{-} \mathrm{NS}_{\mathrm{C}}$ (black and dark grey) allows cooperative binding to DNA molecules (orange lines) that differ in shape. A flexible linker allows the DNA-binding domains (ovals) of different molecules along the H-NS oligomers to interact simultaneously without introducing additional stress either in the DNA molecule or the H-NS oligomer backbone (grey rectangles). The linker of $\mathrm{H}-\mathrm{NS}_{\mathrm{R} 27}$ (red lines, light gray) has a lower flexibility than that of $\mathrm{H}-\mathrm{NS}_{\mathrm{C}}$ when bound to DNA (top right panel, DNA not represented). The bottom panels illustrate the discrimination between different shapes of DNA. The more rigid linker of $\mathrm{H}-\mathrm{NS}_{\mathrm{R} 27}$ allows only the interaction with certain DNA shapes (represented by a straight line, left panel) but not others (bent line). When the long-range shapes of DNA and H-NS oligomers are not compatible, either the interaction of the DNA-binding domain cannot be simultaneously optimized (center) or the H-NS oligomers would have to be distorted away from their optimal geometry (right). For the sake of clarity, the length scale of the DNA distortions and the number of H-NS monomers has been greatly reduced and a realistic representation of the H-NS oligomers has not been attempted. Selectivity resulting from matching long-range oligomer shapes and more complex DNA geometries, such as bridging, would be similarly affected by changes in linker flexibility.

It has been previously shown that isolated DBDs of H-NS and a related protein (Ler) bind DNA with low affinity and recognize local DNA distortions by an indirect readout mechanism. ${ }^{18}$ Long-range cooperative binding by H-NS oligomers may provide a mechanism for sensing long-range DNA distortions, providing the next level of indirect readout with increased selectivity. 
While sequence variations affecting other regions of $\mathrm{H}-\mathrm{NS}_{\mathrm{C}}$ and $\mathrm{H}-\mathrm{NS}_{\mathrm{R} 27}$ may contribute to the distinct selectivity of the two variants, our results suggest that the capacity of the linker region to allow simultaneous interaction with DNA of multiple DBDs in a H-NS oligomer, provides an indirect readout mechanism of long DNA segments. This mechanism may be essential to differentiate between the two broad DNA families encoding core genes and horizontally acquired elements.

\section{Materials and Methods}

\section{Plasmids}

Plasmids pET22b-H-NS $\mathrm{C}_{\mathrm{C}}$ and pET22b-H-NS $\mathrm{R}_{27}$, encoding Salmonella Typhimurium $\mathrm{H}-$ $\mathrm{NS}_{\mathrm{C}}$ and $\mathrm{H}-\mathrm{NS}_{\mathrm{R} 27}$, respectively, have been described. ${ }^{13}$

Plasmids pET22b-H-NS $\mathrm{C}_{\mathrm{C}}$ and $\mathrm{pET} 22 \mathrm{~b}-\mathrm{H}-\mathrm{NS}_{\mathrm{R} 27}$ were used as templates for the production of chimeras. Primer sequences in italics are vector-derived, those in upper case are $\mathrm{H}-\mathrm{NS}_{\mathrm{C}}$-derived and those in lower case are $\mathrm{H}-\mathrm{NS}_{\mathrm{R} 27}$-derived.

Chimera $\alpha$ (oLD) was produced by first amplifying fragment 'o' with an 'L' extension using primer HNSplasmF: 5'-CAT CCA Tat gtc cga agc act caa atc att aaa c-3' vs. oLrev: 5'-CGG ATT TAG CGG CAG CCA Tag aac tca gta act ctt cag ggt c-3' and the

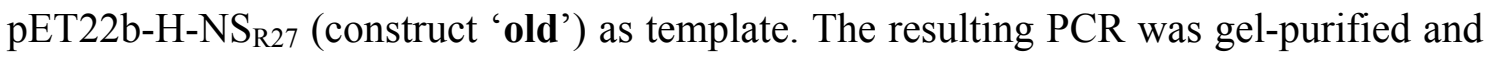
extended vs. HNSchromR: 5'-CTA CGG ATC CTT AGT GGT GGT GGT GGT GGT GTT CCT TGA TCA GGA AAT CTT CC-3' using plasmid pET22b-H-NS (construct $^{2}$ 'OLD') as template.

Chimera $\beta$ (Old) was produced by first amplifying fragment ' $O$ ' with an ' 1 ' extension using primer HNSchromF: 5'-CGT CAT ATG AGC GAA GCA CTT AAA ATT CTG AAC-3' vs. Olrev: 5' '-gtg ctc cgg act ttg cag aga aGC TAT TCA GCA GTT CAT TCG

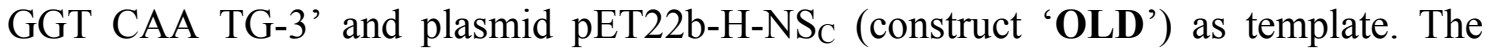
resulting PCR was gel-purified and extended vs. HNSplasmR: 5'-CCT GGG ATC CTT AGT GGT GGT GGT GGT GGT Gga tga gga aat cat cca gtt ttt tac c-3' using plasmid pET22b-H-NS $\mathrm{R} 27$ (construct 'old') as template.

Chimera $\gamma$ (OID) was produced by amplifying fragment ' $O$ ' with an 'l' extension (as previously for 'Old' chimera). Fragment 'ID' was also amplified in a semi-nested reaction using using lfwd: 5'-ttc tct gca aag tcc gga gca cct aaa aaa gtt cgc gaa ccg cgc 
cet geg aaa-3' and 1Dfwd: 5'-gcg aac cge gec ctg cga aaT ATA GCT ATG TTG ACG AAA ACG GTG AAA CT-3' vs. HNSchromR using plasmid pET22b-H-NS (construct 'OLD') as template. The resulting 'Ol' and ' $1 \mathrm{D}$ ' fragments were purified and then extended against each other in the absence of template.

Chimera $\delta(\mathbf{o L d})$ was produced by amplifying fragment ' 0 ' with an 'L' extension (as previously for 'oLD' chimera). Fragment 'Ld' was also amplified in a semi-nested reaction using using Lfwd: 5'-ATG GCT GCC GCT AAA TCC GGT ACC AAA GCT AAA CGC GCA GCT CGT CCG GCT AAA-5' and Ldfwd: 5'-GCT AAA CGC GCA GCT CGT CCG GCT AAA tat aaa tac act gat gtt aat ggt gaa acg aaa acc-3' vs. HNSplasmR using plasmid pET22b-NS ${ }_{\mathrm{R} 27}$ (construct 'old') as template. The resulting ' $\mathrm{oL}$ ' and 'Ld' fragments were purified and then extended against each other in the absence of template.

All chimeric PCR products were digested with NdeI and BamHI and cloned into pET22b as for the parental H-NS constructs.

DNA fragments containing the coding sequence of $\mathrm{H}-\mathrm{NS}_{\mathrm{C}}$ residues 95-137 $\left(\mathrm{H}-\mathrm{NS}_{95 \mathrm{C}}\right)$,

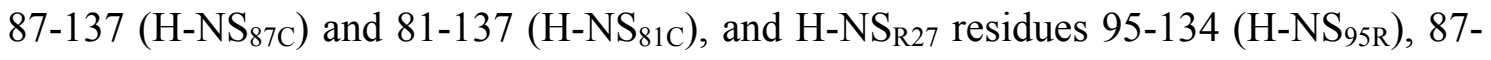
$134\left(\mathrm{H}_{-N S_{87 \mathrm{C}}}\right)$ and 81-134 $\left(\mathrm{H}_{-N S_{81 \mathrm{C}}}\right)$ fused to a C-terminal His 6 -tag were amplified by PCR using the full-length $\mathrm{H}-\mathrm{NS}_{\mathrm{C}}$ and $\mathrm{H}-\mathrm{NS}_{\mathrm{R} 27}$ constructions as templates. The PCR products were subcloned into the NcoI/BamHI sites of the pET14b plasmid following standard protocols.

Point mutations were generated using the QuikChange site-directed mutagenesis kit (Stratagene). All clones were sequenced before use.

\section{Protein expression}

H-NS $\mathrm{C}_{\mathrm{C}}$ was expressed and purified as described previously. ${ }^{13}$ E. coli BL21 (DE3) $\Delta h n s$ strain was used for $\mathrm{H}_{-} \mathrm{NS}_{\mathrm{R} 27}$ expression. ${ }^{13}$ Cells were grown at $37^{\circ} \mathrm{C}$ to an optical density of 0.7 at $600 \mathrm{~nm}$. Then $0.5 \mathrm{mM}$ IPTG (isopropyl $\beta$-D-thiogalactopyranoside) was added and the cells were incubated for another $3 \mathrm{~h}$ for protein expression. After centrifugation, the pellets were resuspended in $20 \mathrm{~mL}$ buffer A $(20 \mathrm{mM}$ HEPES pH 8, $100 \mathrm{mM} \mathrm{NaCl}, 0.5 \mathrm{mM}$ EDTA, $20 \mathrm{mM}$ imidazole) and lysed by freezing and thawing followed by sonication. His-tagged $\mathrm{H}-\mathrm{NS}_{\mathrm{R} 27}$ was purified from the soluble extract with $\mathrm{Ni}^{2+}$-NTA agarose (Qiagen) and eluted with $12 \mathrm{ml}$ of buffer $\mathrm{A}$ in the presence of 400 
$\mathrm{mM}$ imidazole. Eluted fractions were further purified by size-exclusion chromatography on Superdex 75 in buffer B (20 mM sodium phosphate pH 7.5, $300 \mathrm{mM} \mathrm{NaCl}, 0.2 \mathrm{mM}$ EDTA, $\left.0.01 \%(\mathrm{w} / \mathrm{v}) \mathrm{NaN}_{3}\right)$.

Protein chimeras were obtained following the same procedure described for $\mathrm{H}_{-\mathrm{NS}} \mathrm{R}_{27}$. For chimeras containing a cysteine residue $(\beta$ and $\gamma), 15 \mathrm{mM} \beta$-mercaptoethanol and 1 mM TCEP (Tris(2-carboxyethyl)phosphine) was included in buffer A and buffer B, respectively.

Truncated $\mathrm{H}-\mathrm{NS}_{\mathrm{C}}$ and $\mathrm{H}-\mathrm{NS}_{\mathrm{R} 27}$ variants were expressed and purified as previously described for the C-terminal domain of E. coli $\mathrm{H}-\mathrm{NS}{ }^{18}$

Uniform ${ }^{15} \mathrm{~N}$-labelling was achieved by growing the bacteria in M9 minimal medium containing ${ }^{15} \mathrm{NH}_{4} \mathrm{Cl}$ as the sole nitrogen source.

\section{NMR spectroscopy}

All NMR spectra were acquired on a BrukerDMX-500 MHz, Bruker Avance $600 \mathrm{MHz}$ or Bruker Avance $800 \mathrm{MHz}$ spectrometers. Data processing and analysis were carried out with NMRPipe ${ }^{26}$ and NMRViewJ. ${ }^{27}{ }^{1} \mathrm{H}^{15}{ }^{15} \mathrm{NSQC}$ spectra were obtained at $25^{\circ} \mathrm{C}$ with $75 \mu \mathrm{M}$ protein samples and the indicated amount of dsDNA dissolved in $20 \mathrm{mM}$ sodium phosphate (pH 7.5), $150 \mathrm{mM} \mathrm{NaCl}, 0.2 \mathrm{mM}$ EDTA, and $0.01 \%$ (w/v) $\mathrm{NaN}_{3}$. Three dsDNA substrates were used in NMR experiments: hilA 23 (GTC CAT TCG ATA ATC ACA GTT AG/CT AAC TGT GAT TAT CGA ATG GAC), proU 26 (CCA TTG GGT AAT ATA TCG ACA TAG AC/GT CTA TGT CGA TAT ATT ACC CAA TGG) and the self-complementary duplex AATT $_{10}$ d(CGC AAT TGC G). dsDNA was prepared by hybridization of complementary oligonucleotides purchased from SigmaAldrich. Oligonucleotides were mixed in equimolar amounts and annealed by heating to $92^{\circ} \mathrm{C}$ for 4 min and slowly cooled to room temperature.

The binding affinity of the interaction of $\mathrm{H}_{-\mathrm{NS}} \mathrm{S}_{87 \mathrm{R}}$ with hil $\mathrm{A}_{23}$ was estimated by $\mathrm{NMR}$ titration experiments as previously described. ${ }^{16}$

\section{Electrophoretic Mobility Shift Assay (EMSA)}

A 6-FAM ${ }^{\mathrm{TM}}$ labelled forward primer (biomers.net) was used to obtain the $\operatorname{proU}_{540}$ fragment (proU -300 to +240 ) by PCR amplification, as previously described. ${ }^{13}$ Binding reactions were performed by mixing $1 \mu \mathrm{g}$ proU $\mathrm{U}_{540}, 2 \mu \mathrm{l}$ of binding buffer ( $100 \mathrm{mM}$ Tris- 
$\mathrm{HCl} \mathrm{pH}$ 7.5, 5 mM DTT, $100 \mathrm{mM} \mathrm{MgCl} 2,100 \mathrm{mM} \mathrm{KCl,} 100 \mathrm{mM} \mathrm{NaCl}, 50 \%$ glycerol), $1 \mu \mathrm{l}$ of BSA ( $2 \mathrm{mg} / \mathrm{ml})$ and varying protein concentrations. The $\mathrm{NaCl}$ concentration was adjusted to $150 \mathrm{mM}$ (final concentration) with buffer $\mathrm{B}$ and the required volume of water was then added to bring the final volume to $20 \mu 1$.

Protein-DNA mixtures were incubated for 20 minutes at room temperature. Samples were resolved on $3.5 \%$ polyacrylamide gels in TAE buffer at $4{ }^{\circ} \mathrm{C}$ at $100 \mathrm{~V}$ ( $\sim 15$ hours). A 22 x 16.5-cm vertical electrophoresis cell (CBS Scientific, model ASG-250-02) was used.

The 6-FAM ${ }^{\mathrm{TM}}$ fluorophore (excitation max. $=494 \mathrm{~nm}$, emission $\max .=520 \mathrm{~nm}$ ) was used for nucleic acid detection.

\section{Acknowledgements}

We acknowledge fruitful discussions with A. Juarez (University of Barcelona) and M. Falconi (University of Camerino) for introducing C.F.de A. to EMSA experiments. This work was supported by funds from the Spanish MICINN-FEDER (BIO2010-15683), the Generalitat de Catalunya (2009SGR1352) and the 7FP of the EC (Bio-NMR contract 261863). NMR instruments were made available by the Spanish NMR “Instalación Científico Tecnológica Singular" of the University of Barcelona.

\section{References}

1 Sander, P., Springer, B., Prammananan, T., Sturmfels, A., Kappler, M., Pletschette, M. et al. (2002). Fitness cost of chromosomal drug resistance-conferring mutations. Antimicrob. Agents Chemother. 46, 1204-1211.

2 Andersson, D. I. \& Hughes, D. (2010). Antibiotic resistance and its cost: it is possible to reverse resistance? Nat. Rev. Microbiol. 8, 260-271.

3 Dorman, C. J. (2009). Regulatory integration of horizontally-transferred genes in bacteria. Front Biosci. 14, 4103-4112.

4 van Passel, M. W. J., Marri, P. R. \& Ochman, H. (2008). The Emergence and Fate of Horizontally Acquired Genes in Escherichia coli. PLoS Comput Biol 4(4): e1000059. doi:10.1371/journal.pcbi.1000059.

5 Croft, L. J., Lercher, M. J., Gagen, M. J. \& Mattick, J. S. (2003). Is prokaryotic complexity limited by accelerated growth in regulatory overhead? Genome Biol. 5, P2. 
6 Dorman, C. J. (2004). H-NS: A universal regulator for a dynamic genome. Nat. Rev. Microbiol. 2, 391-400.

7 Hommais, F., Krin, E., Laurent-Winter, C., Soutourina, O., Malpertuy, A., Le Caer, J. et al. (2001). Large-scale monitoring of pleiotropic regulation of gene expression by the prokaryotic nucleoid-associated protein H-NS. Mol. Microbiol. 40, 20-3.

8 Navarre, W. W., Porwollik, S., Wang, Y., McClelland, M., Rosen, H., Libby, S. J. et al. (2006). Selective silencing of foreign DNA with low GC content by the H-NS protein in Salmonella. Science, 313, 236-238.

9 Lucchini, S., Rowley, G., Goldberg, M. D., Hurd, D., Harrison, M. \& Hinton, J. C. (2006). H-NS mediates the silencing of laterally acquired genes in bacteria. PloS Pathog. 2(8): e81. doi:10.1371/journal.ppat.0020081.

10 Oshima, T., Ishikawa, S., Kurokawa, K., Aiba, H. \& Ogasawara, N. (2006). H-NS preferentially binds to horizontally acquired DNA in association with RNA polymerase. DNA Res. 13, 141-153.

11 Dorman, C. J. \& Kane, K. A. (2009). DNA bridging and antibridging: a role for bacterial nucleoid-associated proteins in regulating the expression of laterally acquired genes. FEMS Microbiol. Rev. 33, 587-592.

12 Stoebel, D. M., Free, A. \& Dorman, C. J. (2008). Anti-silencing: overcoming H-NS -mediated repression of transcription in gram-negative bacteria. Microbiol. 154, 2533-2545.

13 Baños, R. C., Vivero, A., Aznar, S., García, J., Pons, M., Madrid, C. et al. (2009). Differential regulation of horizontally acquired and core genome genes by the bacterial modulator H-NS. PLoS Genet. 5(6):e1000513. doi:10.1371/journal.pgen.1000513.

14 Bloch, V., Yang, Y., Margeat, E., Chavanieu, A., Auge, M. T., Robert, B. et al. (2003). The H-NS dimerization domain defines a new fold contributing to DNA recognition. Nat. Struct. Biol. 10, 212-218.

15 Arold, S. T., Leonard, P. G., Parkinson, G. N. \& Ladbury J. E. (2010). H-NS forms a superhelical protein scaffold for DNA condensation. Proc. Natl. Acad. Sci. USA 107, 15728-15732.

16 Gordon, B. R., Li, Y., Cote, A., Weirauch, M. T., Ding, P., Hughes, T. R., et al. (2011). Structural basis for recognition of AT-rich DNA by unrelated xenogeneic silencing proteins. Proc. Natl. Acad. Sci. USA 108, 10690-10695. 
17 Shindo, H., Iwaki, T., Ieda, R., Kurumizaka, H., Ueguchi, C., Mizuno, T. et al. (1995). Solution structure of the DNA binding domain of a nucleoid-associated protein, H-NS, from Escherichia coli. FEBS Lett. 360, 125-131.

18 Cordeiro, T. N., Schmidt, H., Madrid, C., Juárez, A., Bernadó, P., Griesinger, C. et al. (2011). Indirect DNA readout by an H-NS related protein: Structure of the DNA complex of the C-terminal domain of Ler. PLoS Pathog. 7(11): e1002380. doi:10.1371/journal.ppat.1002380.

19 Sette, M., Spurio, R., Trotta, E., Brandizi, C., Brandi, A., Pon, C. L. et al. (2009). Sequence-specific recognition of DNA by the C-terminal domain of nucleoidassociated protein H-NS. J. Biol. Chem. 284, 30453-30462.

20 Lang, B., Blot N., Bouffartigues, E., Buckle, M., Geertz, M., Gualerzi, C. O. et al. (2007). High-affinity DNA binding sites for H-NS provide a molecular basis for selective silencing within proteobacterial genomes. Nucleic Acids Res. 35, 63306337.

21 Bouffartigues, E., Buckle, M., Badaut, C., Travers, A. \& Rimsky, S. (2007). H-NS cooperative binding to high-affinity sites in a regulatory element results in transcriptional silencing. Nat. Struct. Mol. Biol. 14, 441-448.

22 Tupper, A. E., Owen-Hughes, T. A., Ussery, D. W., Santos, D. S., Ferguson, D. J. P., Sidebotham, J. M. et al. (1994). The chromatin-associated protein H-NS alters DNA topology in vitro. EMBO J. 13, 258-268.

23 Shindo, H., Ohnuki, A., Ginba, H., Katoh, E., Ueguchi, C., Mizuno, T. et al. (1999). Identification of the DNA binding surface of H-NS protein from Escherichia coli by NMR spectroscopy. FEBS Lett. 455, 63-69.

24 Smyth, C. P., Lundbäck, T., Renzoni, D., Siligardi, G., Beavil, R., Layton, M. et al. (2000). Oligomerization of the chromatin-structuring protein H-NS. Mol. Microbiol. 36, 962-972.

25 Dame, T. D., Luijsterburg, M. S., Krin, E., Bertin, P. N., Wagner, R. \& Wuite, J. L. (2005). DNA bridging: a property shared among H-NS-like proteins. J. Bacteriol. 187, 1845-1848.

26 Delaglio, F., Grzesiek, S., Vuister, G. W., Zhu, G., Pfeifer, J. \& Bax, A. (1995). NMRPipe: A multidimensional spectral processing system based on UNIX pipes. $J$ Biomol NMR, 6, 277-293.

27 Johnson, B. A. (2004). Using NMRView to visualize and analyze the NMR spectra of macromolecules. Methods Mol. Biol. 278, 313-352. 